\title{
The Loop Electrosurgical Excision Procedure and Cone Conundrum: The Role of Cumulative Excised Depth in Predicting Preterm Birth
}

\author{
Danielle M. Panelli, MD ${ }^{1}$ Rachel L. Wood, MD ${ }^{2}$ Kevin M. Elias, MD ${ }^{3}$ Whitfield B. Growdon, MD \\ Anjali J. Kaimal, MD MAS ${ }^{5}$ Sarah Feldman, MD MPH ${ }^{3}$ Thomas F. McElrath, MD PhD ${ }^{2}$
}

\footnotetext{
${ }^{1}$ Division of Maternal-Fetal Medicine, Department of Obstetrics and Gynecology, Stanford University School of Medicine, Stanford, California

2 Division of Maternal-Fetal Medicine, Brigham and Women's Hospital, Harvard Medical School, Boston, Massachusetts

${ }^{3}$ Division of Gynecologic Oncology, Brigham and Women's Hospital, Harvard Medical School, Boston, Massachusetts

${ }^{4}$ Division of Gynecologic Oncology, Massachusetts General Hospital, Harvard Medical School, Boston, Massachusetts

${ }^{5}$ Division of Maternal-Fetal Medicine, Massachusetts General Hospital, Harvard Medical School, Boston, Massachusetts
}

\begin{abstract}
Address for correspondence Danielle M. Panelli, MD, Division of Maternal-Fetal Medicine, Department of Obstetrics and Gynecology, Stanford University School of Medicine, 300 Pasteur Drive, Stanford, CA 94305 (e-mail: dpanelli@stanford.edu).
\end{abstract}

AJP Rep 2022;12:e41-e48.

\section{Abstract \\ Keywords \\ - cervical dysplasia \\ - cervical excision \\ - cervical length \\ - cone biopsy \\ - loop electrosurgical excision procedure \\ - preterm birth}

Objective The objective was to determine factors associated with spontaneous preterm birth at less than 37 weeks in a cohort of patients who underwent a loop electrosurgical excision procedure (LEEP) or cone prior to pregnancy.

Study Design This was a nested case-control study within a cohort of patients who underwent at least one LEEP or cone and had care for the next singleton pregnancy at either of two institutions between 1994 and 2014. Cases had spontaneous preterm birth at less than 37 weeks. Exposures included potential risk factors for preterm birth such as cumulative depth of excised cervix and time since excision. Reverse stepwise selection was used to identify the covariates for multivariable logistic regression.

Results A total of 134 patients were included. Eighteen (13\%) had a spontaneous preterm birth at less than 37 weeks. Median second-trimester cervical lengths were similar between those who delivered preterm and term $(3.9-\mathrm{cm}$ preterm and 3.6-cm term, $p=0.69$ ). Patients who delivered preterm had a significantly greater median total excised depth of cervix ( 1.2 vs. $0.8 \mathrm{~cm}, p=0.04)$. After adjustment for confounders, total excised depth remained significantly associated with preterm birth (adjusted odds ratio $[\mathrm{aOR}]=2.2,95 \%$ confidence interval $[\mathrm{Cl}]: 1.3-3.8$ ).

Conclusion Total excised depth should be considered in addition to cervical length screening when managing subsequent pregnancies. received

August 21, 2020

accepted after revision

October 8, 2021
DOI https://doi.org/

$10.1055 / \mathrm{s}-0041-1742271$. ISSN 2157-6998.

\footnotetext{
(C) 2022. The Author(s).

This is an open access article published by Thieme under the terms of the Creative Commons Attribution-NonDerivative-NonCommercial-License, permitting copying and reproduction so long as the original work is given appropriate credit. Contents may not be used for commercial purposes, or adapted, remixed, transformed or built upon. (https://creativecommons.org/ licenses/by-nc-nd/4.0/)

Thieme Medical Publishers, Inc., 333 Seventh Avenue, 18th Floor, New York, NY 10001, USA
} 
Key Points

- A history of a LEEP or cone excision has been associated with spontaneous preterm birth.

- A two-fold increase in spontaneous preterm birth was seen per cumulative centimeter excised.

- There was no difference in second-trimester cervical length between the term and preterm groups.

As cervical cancer screening has improved over the last 30 years, reproductive-aged patients with cervical dysplasia are increasingly being offered more conservative management options. ${ }^{1}$ Cold-knife cones (cones), often with deeper excisions over $2 \mathrm{~cm}(\mathrm{~cm})$, are less common, as more superficial loop electrosurgical excisional procedures (LEEPs) with an average depth of 5 to $7 \mathrm{~mm}$ ( $\mathrm{mm}$ ) become more prevalent. ${ }^{2,3}$ When excisions were more liberal, there were data suggesting an increased risk of preterm birth. ${ }^{4,5}$ With this evolution toward more shallow excisions, the risk of preterm delivery among women undergoing LEEP or cones may have changed.

In addition to clinical practice changes, heterogeneity in procedure type, number, pathology, and depth make risk stratification for each individual challenging during pregnancy. Short cervical length, defined hereafter as less than or equal to $2.5 \mathrm{~cm}$, has been useful in predicting preterm birth in this population. ${ }^{6-9}$ Cervical length surveillance is often considered for this reason, though timing and frequency are controversial. There is also evidence that cervical dysplasia itself might contribute to preterm birth irrespective of cervical length. ${ }^{4,10}$ As 200,000 patients are diagnosed with high-grade dysplasia annually in the United States, ${ }^{11}$ identification of a comprehensive clinical factor to aid in managing their subsequent pregnancies would be useful. The objective of this study was therefore to describe the spontaneous preterm birth rate among a contemporary cohort who underwent at least one cervical excision prior to pregnancy and to explore the association between clinical factors such as cumulative excised depth of cervix and spontaneous preterm birth.

\section{Methods}

\section{Study Design}

This was a nested case-control study within a cohort of patients who underwent at least one LEEP or cone at either Brigham and Women's Hospital or Massachusetts General Hospital between June 1, 1994, and June 1, 2014, and had prenatal and birth records available for the subsequent pregnancy. Exposures included clinical factors potentially associated with preterm birth, and the cases had spontaneous preterm birth at less than 37 weeks. The Partners Healthcare Institutional Review Board approved this project without the need for informed consent given its retrospective nature (protocol number: 2017P001175).

\section{Patient Population}

A database of patients undergoing a LEEP or cone has been prospectively collected at our institution. A query of this database identified patients who had undergone a cone or a
LEEP before the age of 45 and who had pathology reports available during the selected timeframe. This age cut-off was selected as a subsequent pregnancy after this point was deemed unlikely. Within this cohort, those who had a subsequent pregnancy managed at either institution were identified by searching pregnancy related codes. If a patient only had one excision procedure, the first birth following the excision was used. If a patient had multiple procedures, the birth following the last procedure was used. Patients without complete documentation of both second-trimester cervical length and birth outcome in the electronic medical record, those with a history of preterm birth at less than 37 weeks prior to the cervical excision procedure, those who underwent the procedure during pregnancy, and those with multiple gestations were excluded. If the patient was pregnant at the time of a cervical length performed at or beyond 16 weeks, she was included and any subsequent outcome to the pregnancy was recorded.

\section{Variables}

Data for the cervical excision procedures were obtained directly from operative notes and pathology reports. Operative notes were reviewed to confirm that the procedure was in fact a cone or a LEEP. The depth of cervix excised was taken from pathology reports. By convention at our institutions, the depth of the specimen describes the length of the canal from external os to the area most proximal to the internal os and is listed as the third number in the pathology report after the cross-sectional dimensions of the external face of the cervix. If patients had multiple procedures, the depths taken from each individual pathology report were summed for a cumulative depth of excised cervix per patient. The final pathologic diagnosis was also taken from the pathology reports. If women had multiple excisional procedures between their initial excision and the subsequent pregnancy, the highest grade pathology on any procedure was used for analysis. Due to the timeframe selected, many patients did not have human papilloma virus (HPV) testing sent or reported; given the inconsistency in this variable, HPV status was not included.

Cervical lengths were abstracted from ultrasounds at three time points as follows: (1) from $16^{0 / 7}$ weeks through $20^{0 / 7}$ weeks, (2) from $20^{1 / 7}$ weeks through $24^{0 / 7}$ weeks, and (3) from $24^{1 / 7}$ weeks through $28^{0 / 7}$ weeks. These time points were chosen a priori as women at our institution present for their anatomic survey between 16 and 20 weeks, with the intention to capture any additional clinically relevant potential cervical lengths collected on further screenings. All ultrasounds were performed or attested by board-certified sonologists. In recent years, most patients undergo transabdominal cervical length screening at the anatomy 
ultrasound followed by a transvaginal ultrasound if this appears to be less than $3.0 \mathrm{~cm}$ in length but this is not a standard approach. If a cervical length was not reported on the ultrasound, the images were reviewed and, if needed, the cervical length was measured from the best available image according to current standards by a physician member of the research team. ${ }^{12}$ If patients had multiple cervical lengths recorded during one time period, the first cervical length in the series was used. This approach was selected due to the heterogeneity in cervical length screening protocols in this population over the selected timeframe.

\section{Outcomes}

The primary outcome of interest was spontaneous preterm birth at less than 37 weeks, and those with this outcome were defined as cases. Gestational age was determined from the obstetric estimate recorded in the medical record as determined by last menstrual period and confirmed with ultrasound dating, as all patients had at least one ultrasound on record to be included. Additional obstetric outcomes were abstracted from the birth record, but as this study was not powered to evaluate maternal or neonatal morbidity, we chose to document rather than compare these outcomes.

\section{Statistics}

Analyses were conducted using Chi-squared or Fisher's exact tests for categorical variables and the Wilcoxon's rank-sum test for continuous variables. Covariates that were significant to $p$-value less than or equal to 0.30 were included in reverse stepwise selection to identify the most robust variables to include in the final logistic regression model. We planned a priori to include cervical length and depth as candidate variables in the reverse stepwise selection process, regardless of their $p$-values. A multivariable logistic regression was then performed using these covariates to identify clinical factors independently associated with preterm birth. This method was selected due to the high number of covariates that might be related to preterm birth in this cohort, in an attempt not to over fit the final model. Recognizing this, we planned a sensitivity analysis to analyze the data including all covariates significant to $p$-value less than 0.10 plus cervical length and cerclage.

Next, we divided the cohort in two groups: those with greater than versus less than and equal to the median total excised depth. Obstetric outcomes were compared between these groups. Lastly, we described rates of preterm birth, cerclage, and vaginal progesterone use between patients with and without a short cervical length. Statistical significance was set at a two-tailed $p$-value of less than 0.05. STATA Version 15 (Stata Corp., College Park, TX) was used for all data analysis.

\section{Results}

A total of 1,533 patients underwent excisional cervical procedures during the study period, of whom 134 met inclusion criteria (-Fig. 1). Of these 134 patients, 27 (20\%) had two or more excisional procedures; 48 patients (36\%)

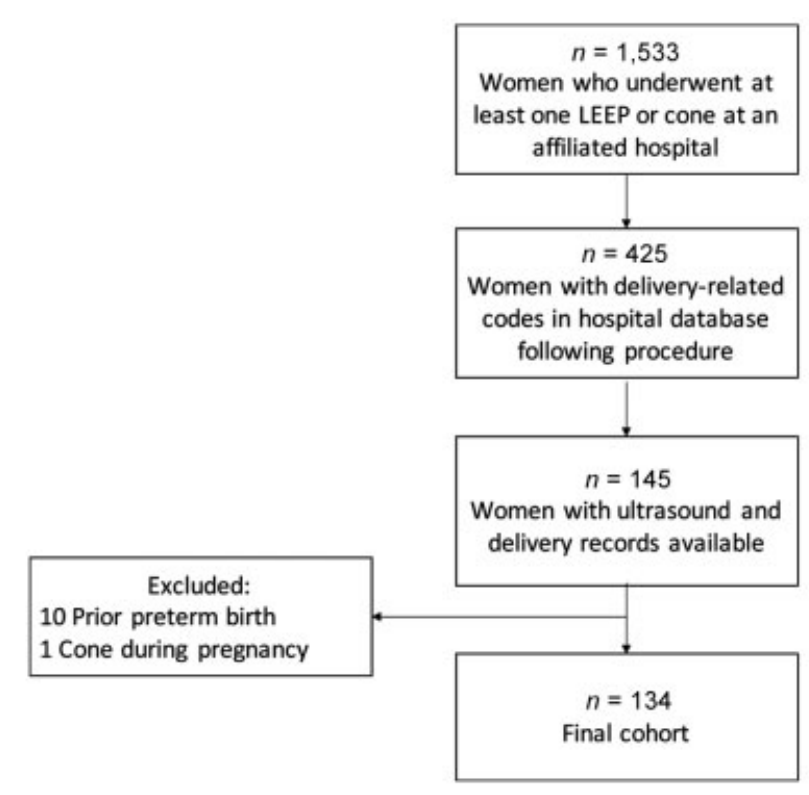

Fig. 1 Flow chart for inclusion in study cohort. LEEP, loop electrosurgical excisional procedures.

had at least one cone done prior to pregnancy (-Table $\mathbf{1}$ ). Among the entire study population, the median total depth of excised cervix was $0.8 \mathrm{~cm}$ (interquartile range [IQR]: 0.5-1.3] and the median duration of time from the last procedure to the subsequent birth was 2.9 years (IQR: 1.8-5.5). The most common pathologic diagnosis was highgrade dysplasia $(n=70,52 \%)$. - Fig. 2 demonstrates the distribution of procedure type over the study period.

At the time of the subsequent pregnancy, most patients were nulliparous and had conceived spontaneously (-Table 1). The median second-trimester cervical lengths for the entire cohort were normal at 16 to 20 weeks $(3.6 \mathrm{~cm}$, IQR: $3.2-4.0 \mathrm{~cm}$ ). Of note, no patient with a cervical length greater than $3.0 \mathrm{~cm}$ between 16 and 20 weeks had a cervical length of less than $2.5 \mathrm{~cm}$ on follow-up between 20 and 24 weeks. For this reason, and the fact that the majority of patients had a cervical length between 16 and 20 weeks, no further analyses were done using the cervical lengths beyond 20 weeks. Twenty-one of the 134 (15.7\%) cervical lengths between 16 and 20 weeks were transabdominal only.

Preterm birth before 37 weeks occurred in 18 pregnancies (13\%). All preterm births were related to spontaneous labor, cervical dilation, or preterm premature rupture of membranes. Patients who delivered preterm had a greater median cumulative excised depth from all procedures $(1.2-\mathrm{cm}$ excised among those with preterm birth vs. $0.8 \mathrm{~cm}$ among those without, $p=0.04)$. Patients delivering preterm were also more likely to have had two or more procedures ( $44 \%$ in preterm group vs. $16 \%$ in term, $p=0.010$ ) and be older at the time of birth ( 34.7 vs. 31.0 years, $p=0.016$ ). Median secondtrimester cervical lengths were $3.9 \mathrm{~cm}$ among those who delivered preterm and $3.6 \mathrm{~cm}$ among those who delivered at term $(p=0.692)$. Only eight patients $(6 \%)$ had a secondtrimester cervical length less than or equal to $2.5 \mathrm{~cm}$; of these, three (38\%) delivered before 37 weeks. 
Table 1 Demographic, oncologic, and obstetric characteristics among the cohort

\begin{tabular}{|c|c|c|c|c|}
\hline Characteristic & $\begin{array}{l}\text { Whole cohort }{ }^{\mathrm{a}} \\
(n=134)\end{array}$ & $\begin{array}{l}\text { Spontaneous preterm } \\
\text { birth }<37 \text { weeks } \\
(n=18)\end{array}$ & $\begin{array}{l}\text { Term birth } \\
(n=116)\end{array}$ & $p$-Value ${ }^{\mathrm{b}}$ \\
\hline Age at first procedure & $26.0(23.0-30.0)$ & $29.1(24.0-32.0)$ & $26.0(22.9-30.0)$ & 0.196 \\
\hline Age at delivery & $31.3(27.5-40.6)$ & $34.7(32.2-36.8)$ & $31.0(38.4-40.1)$ & 0.016 \\
\hline Race/ethnicity & & & & 0.210 \\
\hline White & $52(39)$ & $11(61)$ & $41(35)$ & \\
\hline Hispanic & $41(31)$ & $4(22)$ & $37(32)$ & \\
\hline Asian & $10(8)$ & $1(6)$ & $9(8)$ & \\
\hline Black & $1(1)$ & 0 & $1(1)$ & \\
\hline Other or declined & $30(22)$ & $2(11)$ & $28(24)$ & \\
\hline \multicolumn{5}{|l|}{ Smoking status } \\
\hline Former smoker & $42(31)$ & $9(50)$ & $33(28)$ & 0.164 \\
\hline Current smoker & $25(19)$ & $2(11)$ & $23(20)$ & 0.617 \\
\hline \multicolumn{5}{|l|}{ Prior cervical procedures } \\
\hline Total number of prior procedures & & & & 0.010 \\
\hline One LEEP or cone & $107(80)$ & $10(56)$ & $97(84)$ & \\
\hline Two or more LEEPs or cones & $27(20)$ & $8(44)$ & $19(16)$ & \\
\hline At least one prior cone ${ }^{c}$ & $48(36)$ & $8(44)$ & $40(34)$ & 0.064 \\
\hline Median total excised depth $(\mathrm{cm})^{\mathrm{d}}$ & $0.8(0.5-1.3)$ & $1.2(0.5-3.0)$ & $0.8(0.5-1.2)$ & 0.038 \\
\hline Worst pathology ${ }^{\mathrm{e}}$ & & & & 0.087 \\
\hline Benign & $20(15)$ & $3(17)$ & $17(15)$ & \\
\hline Low-grade dysplasia & $15(11)$ & $2(11)$ & $13(11)$ & \\
\hline High-grade dysplasia & $70(52)$ & $6(33)$ & $64(55)$ & \\
\hline Adenocarcinoma in situ & $22(16)$ & $5(28)$ & $17(15)$ & \\
\hline Adenocarcinoma & $3(2)$ & $0(0)$ & $3(3)$ & \\
\hline Squamous cell carcinoma & $3(2)$ & $2(11)$ & $1(1)$ & \\
\hline Other or nondiagnostic & $1(1)$ & $0(0)$ & $1(1)$ & \\
\hline Nulliparous at time of pregnancy & $63(47)$ & $11(61)$ & $52(45)$ & 0.198 \\
\hline Median prepregnancy BMI $\left(\mathrm{kg} / \mathrm{m}^{2}\right)$ & $26.5(23.2-29.9)$ & $24.7(21.4-27.9)$ & $26.6(23.4-29.9)$ & 0.273 \\
\hline Time from last procedure to pregnancy (y) & $2.9(1.8-5.5)$ & $3.5(2.2-7.9)$ & $2.8(1.7-5.3)$ & 0.185 \\
\hline Use of assisted reproductive technology ${ }^{f}$ & $15(12)$ & $5(29)$ & $10(9)$ & 0.017 \\
\hline Second-trimester cervical length $(\mathrm{cm})$ & $3.6(3.2-4.0)$ & $3.9(3.1-4)$ & $3.6(3.3-4.0)$ & 0.692 \\
\hline
\end{tabular}

Abbreviations: BMI, body mass index; LEEP, loop electrosurgical excisional procedures.

${ }^{a}$ Continuous variables listed as median with interquartile range. Percentages rounded to nearest whole number and listed as column percent.

bWilcoxon's rank-sum, Chi-square, or Fisher's exact test as appropriate.

Includes cold knife or loop cones.

${ }^{d}$ If patient only had one procedure, the excised depth obtained from the pathology report is listed. If the patient had more than one procedure, the total depth obtained from adding each individual depth is listed.

$\mathrm{e}_{\text {If }}$ an individual had more than one procedure, the highest grade pathology is reported for each patient.

fDenominator is 126 total, 17 in preterm birth and 109 in term birth groups due to 8 with unknown conception type. Since this covariate was not used in the final model, observations with missing conception type were not excluded.

Significant covariates with a $p$-value of less than or equal to 0.30 on bivariate analysis were then included in reverse stepwise selection. The variables selected were total excised depth, maternal age at delivery, smoking status, time between procedure and delivery, cervical length, use of cerclage, parity, race/ethnicity, body mass index, number of procedures, worst pathology, and use of assisted reproduc- tive technology. Using this approach, cervical length, cerclage, parity, race/ethnicity, body mass index, number of procedures, worst pathology, and use of assisted reproductive technology were removed from the model. The final multivariable model therefore included total excised depth, maternal age at delivery, smoking status, and time between procedure and delivery as the strongest covariates. In this 

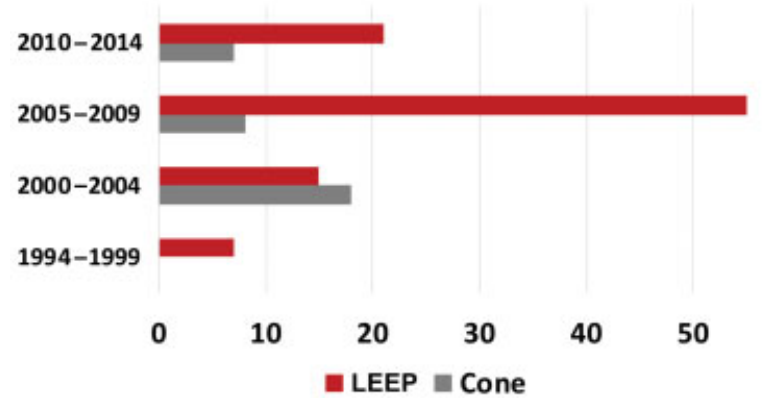

60

Fig. 2 Number of LEEPs and cones over time, in 5-year intervals, 1994-2004. LEEP, loop electrosurgical excisional procedures.

Table 2 Risk factors for spontaneous preterm birth at $<37$ weeks

\begin{tabular}{|l|l|l|l|}
\hline Variable & $\begin{array}{l}\text { Unadjusted odds } \\
\text { ratio }(95 \% \mathrm{Cl})\end{array}$ & $\begin{array}{l}\text { Adjusted odds } \\
\text { ratio }^{\mathrm{a}} \text { (95\% CI) }\end{array}$ & -Value \\
\hline $\begin{array}{l}\text { Cumulative depth } \\
\text { excised }\end{array}$ & $2.2(1.3-3.7)$ & $2.2(1.3-3.8)$ & $<0.01$ \\
\hline $\begin{array}{l}\text { Maternal age at } \\
\text { delivery }\end{array}$ & $1.1(1.0-1.24)$ & $1.1(1.0-1.2)$ & 0.13 \\
\hline Former smoker & $3.0(1.0-8.9)$ & $2.9(1.0-8.8)$ & 0.06 \\
\hline $\begin{array}{l}\text { Time between } \\
\text { procedure } \\
\text { and birth }\end{array}$ & $1.1(0.9-1.3)$ & $1.1(0.9-1.3)$ & 0.30 \\
\hline
\end{tabular}

Abbreviation: $\mathrm{Cl}$, confidence interval.

${ }^{\text {a }}$ Covariates with a $p$-value $\leq 0.30$ were included in reverse stepwise selection. The variables selected were total excised depth, maternal age at delivery, smoking status, time between procedure and delivery, cervical length, use of cerclage, parity, race/ethnicity, body mass index, number of procedures, worst pathology, and use of assisted reproductive technology. Using this approach, total excised depth, maternal age at delivery, smoking status, and time between procedure and delivery emerged as the strongest covariates and were included in the final adjusted model.

multivariable logistic regression, only total excised depth remained significantly associated with preterm birth (adjusted odds ratio $[\mathrm{aOR}]=2.2,95 \%$ confidence interval $[\mathrm{CI}]$ : 1.3-3.8, $p<0.01$; - Table 2).

Next, we performed a sensitivity analysis including significant covariates with a $p$-value of less than 0.10 in our multivariable model. These covariates were total excised depth, two or more procedures, use of assisted reproductive technology, and maternal age at delivery. We ran the model with these covariates, then added cervical length, then added cerclage to see if these altered the results identified in our primary analysis. In all three regression models, only median excised total depth of cervix remained significantly associated with preterm birth (final model: $\mathrm{aOR}=1.97,95 \% \mathrm{CI}$ : 1.01-3.81).

Obstetric outcomes by depth of excised cervix are shown in - Table 3. The groups were divided by whether they had greater or less than the median excised depth of $0.8 \mathrm{~cm}$. Of note, there was no significant difference in cervical length at 16 to 20 or 20 to 24 weeks between patients with less versus more depth of cervix excised ( $p=0.897$ and 0.669 , respectively).
- Table 4 demonstrates interventions and obstetric outcomes by second trimester cervical length. Five (63\%) of the eight patients with a short cervical length had an intervention; four had a cerclage and 1 was managed with vaginal progesterone. Interestingly, 19 of the 126 patients without a short cervical length were also offered an intervention during their pregnancy. Three (38\%) of the 8 patients with short cervical length had a spontaneous preterm birth prior to 37 weeks compared with 15 (12\%) of the 126 patients with a normal cervical length, though this difference did not reach significance $(p=0.074)$.

\section{Discussion}

In this cohort of patients who underwent at least one cervical excision procedure prior to pregnancy, each centimeter of total excised depth of cervix was associated with a two-fold increased odds of spontaneous preterm birth before 37 weeks. However, there was no significant difference in second-trimester cervical length on routine ultrasound examination between those who delivered preterm and those who delivered at term; that being said, with so few patients having a short cervix, we are underpowered to comment on the role of cervical length in predicting preterm birth in this population. The fact that this risk persists even among a cohort with mostly normal second-trimester cervical lengths, suggesting cervical length on ultrasound may not fully capture the risk of preterm birth in this population. ${ }^{13,14}$

Our results demonstrate a persistent risk of preterm birth despite a normal cervical length in patients with a history of cervical excision. That being said, there was a trend toward preterm birth in the patients who had a short cervical length, as has been previously reported by others. ${ }^{6,7,15-17}$ In one study, Berghella et al prospectively enrolled pregnant patients with at least one prior cervical conization to follow their cervical lengths and birth outcomes. Of these patients, $28 \%$ had a cervical length of less than $2.5 \mathrm{~cm}$. Among patients with cervical length less than $2.5 \mathrm{~cm}$ in whom excisional biopsy was the only risk factor for preterm birth, the relative risk for preterm birth less than 35 weeks was 5.43 (95\% CI: $1.57-20.47){ }^{6}$ Of the eight patients (6\%) in our cohort with a cervical length less than or equal to $2.5 \mathrm{~cm}$, three (38\%) delivered before 37 weeks. The remaining 15 patients who delivered preterm had a normal cervical length. While the presence of a short cervix did identify patients at a heightened risk of preterm birth, our data suggest that this metric is not sufficient; in our study, most preterm births were among patients with a normal cervical length.

For context, the majority of births in our cohort occurred between 2005 and 2014, during which time the preterm birth rate in Massachusetts was between 8 and $10 \%{ }^{18}$ While this is similar to the rate of $13 \%$ in our study, all of the preterm births in our cohort were related to spontaneous labor or preterm premature rupture of membranes. In contrast, for national statistics, preterm birth rates usually include medically indicated preterm births which may account for up to $40 \%$ of the preterm births reported. ${ }^{19,20}$ In light of this, the $13 \%$ preterm birth rate related to 
Table 3 Pregnancy outcomes among entire cohort by cumulative depth of excised cervix

\begin{tabular}{|c|c|c|c|c|}
\hline Selected obstetric outcomes & $\begin{array}{l}\text { Whole cohort } \\
(n=134)\end{array}$ & $\begin{array}{l}\leq 0.8-\mathrm{cm} \text { total } \\
\text { depth of excised } \\
\text { cervix }^{\mathrm{a}}(n=63)\end{array}$ & $\begin{array}{l}>0.8-\mathrm{cm} \text { total } \\
\text { depth of excised } \\
\text { cervix }(n=71)\end{array}$ & $p$-Value ${ }^{b}$ \\
\hline \multicolumn{5}{|l|}{ Median second-trimester cervical length } \\
\hline Cervical length $16^{0 / 7}-20^{0 / 7}$ weeks $(n=134)$ & $3.6(3.3-4.0)$ & $3.6(3.3-4.0)$ & $3.6(3.2-4.0)$ & 0.897 \\
\hline Cervical length $20^{1 / 7}-24^{0 / 7}$ weeks $(n=82)$ & $3.5(3.2-4.0)$ & $3.5(3.2-4.0)$ & $3.6(3.1-4.0)$ & 0.669 \\
\hline Any cerclage & $22(16)$ & $7(11)$ & $15(21)$ & 0.602 \\
\hline Transvaginal cerclage & $17(13)$ & $3(5)$ & $14(20)$ & \\
\hline Transabdominal cerclage & $7(5)$ & $5(8)$ & $2(3)$ & \\
\hline \multicolumn{5}{|l|}{ Other interventions } \\
\hline Vaginal progesterone & $6(5)$ & $3(5)$ & $3(4)$ & 0.836 \\
\hline Pessary & $1(1)$ & 0 & $1(1)$ & 0.488 \\
\hline${\text { Gestational age at delivery }{ }^{\mathrm{d}}}$ & $39.9(37.6-39.9)$ & $39.0(38.0-40.0)$ & $39.1(37.5-39.9)$ & 0.547 \\
\hline Preterm birth $<37$ weeks & $18(13)$ & $5(8)$ & $13(18)$ & 0.126 \\
\hline Preterm birth $<32$ weeks & $4(3)$ & $1(2)$ & $3(4)$ & 0.622 \\
\hline $\begin{array}{l}\text { Spontaneous rupture of membranes } \\
\text { on admission }\end{array}$ & $40(32)$ & $17(27)$ & $23(32)$ & 0.549 \\
\hline Mode of delivery & & & & 0.113 \\
\hline Spontaneous vaginal delivery & $90(67)$ & $43(68)$ & $47(66)$ & \\
\hline Operative vaginal delivery & $20(15)$ & $13(21)$ & $7(10)$ & \\
\hline Cesarean delivery & $23(17)$ & $7(11)$ & $16(23)$ & \\
\hline Dilation and evacuation & $1(1)$ & 0 & $1(1)$ & \\
\hline Postpartum hemorrhage ${ }^{\mathrm{e}}$ & $5(4)$ & $2(3)$ & $3(4)$ & 0.675 \\
\hline
\end{tabular}

${ }^{\mathrm{a}} 0.8 \mathrm{~cm}$ was the median depth excised among the entire cohort.

bWilcoxon's rank-sum, Chi-square, or Fisher's exact test as appropriate.

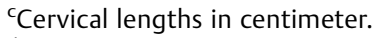

${ }^{\mathrm{d} C}$ Continuous variables listed as median with interquartile range.

${ }^{e}$ Defined as $>500 \mathrm{cc}$ for vaginal birth or $>1,000 \mathrm{cc}$ for cesarean birth.

Table 4 Management and outcomes by cervical length

\begin{tabular}{|l|l|l|l|}
\hline & $\begin{array}{l}\text { Women with } \\
\text { second-trimester } \\
\text { cervical length } \\
\leq 2.5 \mathrm{~cm} \\
(\mathbf{n}=8)\end{array}$ & $\begin{array}{l}\text { Women with } \\
\text { second-trimester } \\
\text { cervical length } \\
>2.5 \mathrm{~cm} \\
(\boldsymbol{n}=126)\end{array}$ & $p$-Value \\
\hline $\begin{array}{l}\text { Spontaneous } \\
\text { preterm } \\
\text { birth }<37 \text { weeks }\end{array}$ & $3(38)$ & $15(12)$ & 0.074 \\
\hline $\begin{array}{l}\text { Spontaneous } \\
\text { preterm } \\
\text { birth }<32 \text { weeks }\end{array}$ & $1(13)$ & $3(2)$ & 0.221 \\
\hline Any Intervention & $5(63)$ & $19(15)$ & 0.005 \\
\hline Cerclage & $4(50)$ & $18(14)$ & \\
\hline $\begin{array}{l}\text { Vaginal } \\
\text { progesterone }\end{array}$ & $1(13)$ & $1(1)$ & \\
\hline
\end{tabular}

${ }^{\text {a}}$ Fisher's exact test.

spontaneous labor or preterm premature rupture of membranes in our cohort does appear to be higher than the rate of spontaneous preterm birth among the baseline population.
The finding that the total summed depth of excised cervix was associated with preterm birth, while cervical length was not suggest that other nonstructural factors are playing a role in the etiology of preterm birth in this population. It could be that, rather than a physical shortening effect, larger excisions cause a greater loss of stroma and glands that result in decreased cervical tensile strength and increased susceptibility to infection during pregnancy. Scarring along the length of the excision may also contribute to loss of cervical plasticity, or perhaps underlying immunologic variables associated with persistent HPV infection may be associated with both dysplasia and preterm labor. An association between excised depth of cervix and preterm birth was also identified by Castanon et al in a cohort of patients in the United Kingdom who underwent colposcopy. ${ }^{21}$ Similar findings have been demonstrated in other studies, though notably the simultaneous incorporation of cervical length and total excised depth is rare. ${ }^{5,13,17,22-24}$ This prior data, in concert with our findings, advocate that the total cumulative excised depth of cervix should be considered a risk factor for preterm birth during prenatal visits. Furthermore, the association between total excised depth of cervix and preterm 
birth supports current practice trends favoring LEEPs where applicable. However, the benefit of performing more shallow excisions in reproductive-aged patients' needs to be weighed against the risk of residual dysplasia and the need for multiple procedures which would also contribute to total depth of excised cervix.

Our findings must be interpreted within the context of our study design. Our sample size is within range of what has been described in other nonpopulation-based studies, but it does limit our ability to adjust for multiple potential confounders simultaneously. We attempted to address this issue by performing a reverse stepwise selection to optimize the relevance of the covariates and by performing a sensitivity analysis. We could also be underpowered with this sample size to detect an association between cervical length and preterm birth; despite this, we were still able to identify a significant difference in total excised depth. Given the small sample of pregnancies after excision available to us retrospectively, our results should be considered exploratory and replicated prospectively to test the predictive utility of cervical length and excised depth in clinical practice. While a larger, prospective study is warranted to validate our results, in the light of national trends, it is unlikely that larger cohorts with this degree of granularity will be available in the future.

\section{Strengths and Limitations}

The strengths of this study include the applicability of our results to clinical practice. Pathology reports would be the most realistic source for practitioners to reference when incorporating excised depth of cervix in their own management strategies. Our approach of summing the depth from multiple excisions can be applied by any practitioner who has the pathology reports from excisional procedures available. Furthermore, the results support future research focusing on the qualitative changes to the cervix after high grade dysplasia and cervical excision. In addition, we did not have consistent records of HPV status to adjudicate our results; this would be an additional variable of interest for future research on preterm birth in this population. We were also not powered to compare maternal or neonatal morbidity among this cohort and have accordingly only included absolute rates of outcomes if available.

\section{Conclusion}

Our results demonstrate total cumulative excised depth to be a unique clinical factor associated with preterm birth in patients with at least one prior cervical excision procedure, independent of second-trimester cervical length. A normal second-trimester cervical length may not provide an accurate assessment of preterm birth risk for these patients. Therefore, total excised depth may be a useful tool to consider in addition to second trimester cervical length screening when managing pregnancy for patients with a prior cervical excision.

\section{Note}

This study was previously presented as an oral presentation at the Society for Maternal-Fetal Medicine's 40th Annual Pregnancy Meeting, February 3-8, 2020, Grapevine, TX.

\section{Conflict of Interest}

The authors report no conflicts of interest nor financial disclosures.

\section{References}

1 Barken SS, Rebolj M, Andersen ES, Lynge E. Frequency of cervical intraepithelial neoplasia treatment in a well-screened population. Int J Cancer 2012;130(10):2438-2444

2 Martin-Hirsch PPL, Paraskevaidis E, Bryant A, Dickinson HO. Surgery for cervical intraepithelial neoplasia. Cochrane Database Syst Rev 2013;2013(12):CD001318

3 Sopracordevole F, Clemente N, Delli Carpini G, et al. Trend of decreasing length of cervical cone excision during the last 20 years. Eur Rev Med Pharmacol Sci 2017;21(21):4747-4754

4 Sasieni P, Castanon A, Landy R, et al. Risk of preterm birth following surgical treatment for cervical disease: executive summary of a recent symposium. BJOG 2016;123(09): 1426-1429

5 Kyrgiou M, Athanasiou A, Kalliala IEJ, et al. Obstetric outcomes after conservative treatment for cervical intraepithelial lesions and early invasive disease. Cochrane Database Syst Rev 2017;11: CD012847

6 Berghella V, Pereira L, Gariepy A, Simonazzi G. Prior cone biopsy: prediction of preterm birth by cervical ultrasound. Am J Obstet Gynecol 2004;191(04):1393-1397

7 Poon LCY, Savvas M, Zamblera D, Skyfta E, Nicolaides KH. Large loop excision of transformation zone and cervical length in the prediction of spontaneous preterm delivery. BJOG 2012;119(06): 692-698

8 Pils S, Eppel W, Seemann R, Natter C, Ott J. Sequential cervical length screening in pregnancies after loop excision of the transformation zone conisation: a retrospective analysis. BJOG 2014; 121(04):457-462

9 Miller ES, Grobman WA. The association between cervical excisional procedures, midtrimester cervical length, and preterm birth. Am J Obstet Gynecol 2014;211(03):242.e1-242.e4

10 El-Bastawissi AY, Becker TM, Daling JR. Effect of cervical carcinoma in situ and its management on pregnancy outcome. Obstet Gynecol 1999;93(02):207-212

11 McClung NM, Gargano JW, Park IU, et al; HPV-IMPACT Working Group. Estimated number of cases of high-grade cervical lesions diagnosed among women-United States, 2008 and 2016. MMWR Morb Mortal Wkly Rep 2019;68(15):337-343

12 Kagan KO, Sonek J. How to measure cervical length. Ultrasound Obstet Gynecol 2015;45(03):358-362

13 Bjørge T, Skare GB, Bjørge L, Tropé A, Lönnberg S. Adverse pregnancy outcomes after treatment for cervical intraepithelial neoplasia. Obstet Gynecol 2016;128(06):1265-1273

14 Kyrgiou M, Koliopoulos G, Martin-Hirsch P, Arbyn M, Prendiville W, Paraskevaidis E. Obstetric outcomes after conservative treatment for intraepithelial or early invasive cervical lesions: systematic review and meta-analysis. Lancet 2006;367(9509):489-498

15 Leiman G, Harrison NA, Rubin A. Pregnancy following conization of the cervix: complications related to cone size. Am J Obstet Gynecol 1980;136(01):14-18

16 Sjøborg KD, Vistad I, Myhr SS, et al. Pregnancy outcome after cervical cone excision: a case-control study. Acta Obstet Gynecol Scand 2007;86(04):423-428 


\section{e48 Role of Cumulative Excised Depth in Predicting Preterm Birth Panelli et al.}

17 Sadler L, Saftlas A, Wang W, Exeter M, Whittaker J, McCowan L. Treatment for cervical intraepithelial neoplasia and risk of preterm delivery. JAMA 2004;291(17):2100-2106

18 March of dimes 2010 premature birth report card. Accessed December 21, 2021: https://www.purdue.edu/hhs/hdfs/fii/ wp-content/uploads/2015/07/s_lafis03c01.pdf

19 Ananth CV, Wilcox AJ, Gyamfi-Bannerman C. Obstetrical interventions for term first deliveries in the US. Paediatr Perinat Epidemiol 2013;27(05):442-451

202019 March of dimes report card. Accessed December 21, 2021: https://www.marchofdimes.org/materials/MOD2019_REPORT_CARD_and_POLICY_ACTIONS_BOOKLETV72.pdf

21 Castanon A, Landy R, Brocklehurst P, et al; PaCT Study Group. Risk of preterm delivery with increasing depth of excision for cervical intraepithelial neoplasia in England: nested case-control study. BMJ 2014;349:g6223

22 Liverani CA, Di Giuseppe J, Clemente N, et al. Length but not transverse diameter of the excision specimen for high-grade cervical intraepithelial neoplasia (CIN 2-3) is a predictor of pregnancy outcome. Eur J Cancer Prev 2016;25(05):416-422

23 Nam KH, Kwon JY, Kim Y-H, Park Y-W. Pregnancy outcome after cervical conization: risk factors for preterm delivery and the efficacy of prophylactic cerclage. J Gynecol Oncol 2010;21(04):225-229

24 Noehr B, Jensen A, Frederiksen K, Tabor A, Kjaer SK. Depth of cervical cone removed by loop electrosurgical excision procedure and subsequent risk of spontaneous preterm delivery. Obstet Gynecol 2009;114(06):1232-1238 